\title{
OPTIMIZATION OF DIRECTIONAL CONTROL VALVES THROUGH DOWNSTREAM COMPENSATION APPROACH
}

\author{
Davide Mesturini ${ }^{1 *}$, Cesare Dolcin ${ }^{1}$, Ulderico Busani ${ }^{1}$, Pietro Marani ${ }^{2}$, Antonella \\ Bonavolontà ${ }^{3}$, Emma Frosina ${ }^{3}$ \\ ${ }^{1}$ Walvoil SpA, via Adige 13/D, 42124 Reggio Emilia, Italy \\ ${ }^{2}$ C.N.R.-IMAMOTER, Via Canalbianco 28, 44124 Cassana (FE), Italy \\ ${ }^{3}$ UniNA FPRG, Università degli Studi di Napoli "Federico II", via Claudio 21, 80125 Napoli \\ *E-mail address: mesturini.d@walvoil.com
}

\begin{abstract}
Various academic studies show that in the use of common ICE Off-road Vehicles only about 10-15\% of the available power at fuel level is actually transformed into useful energy for the actuators.

Particularly the Directional Control Valves are responsible for the dissipation of about $35-40 \%$ of the hydraulic energy available at the pump level.

The machine electrification trend makes it even more urgent to optimize the hydraulic system to ensure greater performance and higher battery autonomy.

Traditional Directional Control Valves design solutions neglect important opportunities for reducing losses and improve internal regeneration. Especially, energy recovery is rarely applied and in any case by means of important superstructures which considerably increase the costs of the system.

This paper presents an innovative Directional Control Valve layout, based on the Downstream Compensation approach that, in a simple and cost-effective design, allows to recover a considerable amount of energy from both the inertial loads and the simultaneous use of multiple actuators at different pressure level.
\end{abstract}

The proposed layout performance and efficiency are studied through lumped element simulation and laboratory experimental tests.

Keywords: Directional control valve; Energy recovery; Accumulator; Efficiency; Downstream Compensation.

\section{PREMISES}

Energy optimization and consumption reduction are the trends that have been driving the evolution of the off-highway sector over the last few years. On the one hand, the regulations set increasingly stringent limits for ICE pollutant emissions. On the other hand, the growing market attention and the increasingly widespread limitations on the use of diesel engines in urban and protected areas are driving the electrification success, as its cost of ownership is getting more and more convenient.

Much effort has been taken into the electrification of machines driveline, but still few solutions have been successfully implemented for the optimization of the hydraulic circuit; many electrified or hybrid vehicles simply change the primary energy source from ICE to electric motor without reconsidering the large possibilities to improve the hydraulic system.

New needs and more demanding machines performance probably require today a new generation of optimized and focused hydraulic components.

In fact, as many studies demonstrate, the traditional hydraulic circuits are responsible for dissipating a huge percentage of the available energy. The advantage of a simple hydraulic system is always connected to the disadvantage of large energy losses [1]. Different Hybrid solutions [2][3] and new operating strategies [4][5] have been realized through the years. However, from these studies emerged that for construction machinery, only a $10-15 \%$ of the available energy is converted into useful work. According to Lodewyks et al. [1] the directional control valve is one of the main responsible for 
this energy waste: the distribution of a single pump flow to multiple users and the control of the speed of overrunning loads are the principal causes. This aspect also emerged in [6], in which the valve group contributes to $35-40 \%$ of the energy dissipation in the hydraulic circuit. Additional energy is lost in the pump efficiency, in the hoses and in the cylinders friction.

Academic literature has proposed as a solution to this problem the "valveless" circuits, removing the directional control valve and providing a dedicated hydraulic energy source for each actuator [1][4][7]. The solution, although brilliant from the theoretical point of view, has to deal with high costs and system complexity and, on balance, it appears to have a difficult implementation.

The directional control valve therefore turns out to be the component with greater opportunity to recover a part of this energy loss.

According to [8], through a comparison of different recovery systems for hydraulic mobile machines emerged in the last years, the greatest opportunity for energy saving lies in the recovery from available energy sources, particularly from inertial loads control [9][10] and from compensation in simultaneous movements.

\section{SYSTEM ARCHITECTURE}

Figure 1 shows the hydraulic schematic of the new proposed solution.

The new concept derives from a typical Load Sensing directional control valve layout. The main spool selects along its stroke the LS signal from user's ports. The highest LS signal is then delivered to a conventional variable Load Sensing pump, which supplies flow at delivery pressure $\mathrm{p}$ equal to LS plus a fixed margin $\Delta \mathrm{p}_{\mathrm{IN}}$. The meter in notches area $A_{I N}$ in the main spool define the flow QIN delivered to the user.

$$
Q_{I N} \propto A_{I N} \cdot \sqrt{\Delta p_{I N}}
$$

\subsection{Downstream compensator}

According to the suggested design, the local compensator spool of every working section is located downstream of the main spool meter out notches Aout.

Analogous compensator configurations have been presented in recent studies [11], but with different pump control logic and energy recovery strategy.

The downstream position of the compensator allows to control the return flow Qout: the compensator guarantees a fixed pressure drop $\Delta$ pout across the main spool discharge notches

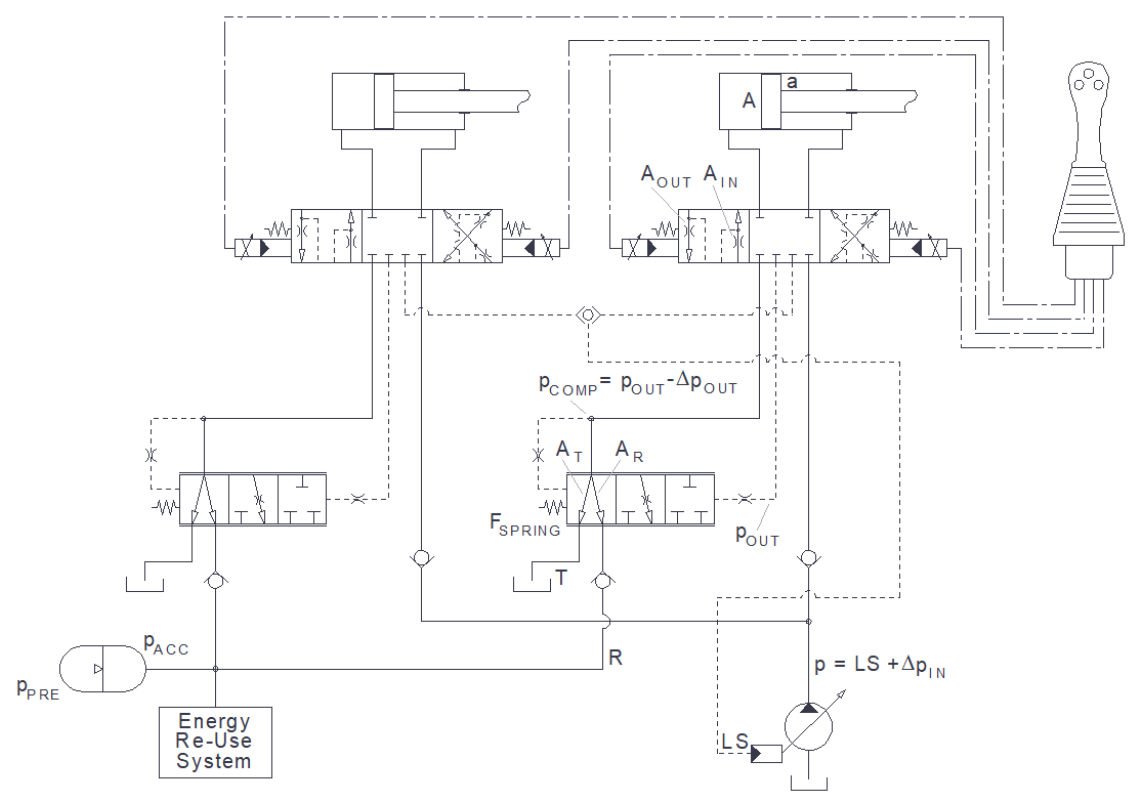

Figure 1: Complete hydraulic schematic 
Aout. Thanks to a couple of pilot pressure signals, acting on identical areas $\mathrm{A}_{\mathrm{PIL}}$ and taken before (pоuт) and after (pсомP) the main spool, the pressure drop is controlled according to the spring force $\mathrm{F}_{\text {SPRING: }}$

$$
\begin{aligned}
& p_{\text {COMP }} \cdot A_{P I L}+F_{\text {SPRING }}=p_{\text {OUT }} \cdot A_{P I L} \\
& Q_{\text {OUT }} \propto A_{\text {OUT }} \cdot \sqrt{p_{\text {OUT }}-p_{\text {COMP }}}
\end{aligned}
$$

The particular embodiment of the compensator is characterized by the presence of three ways, which allow the main spool discharge line to be connected respectively to the system tank $\mathrm{T}$ or to an energy recovery line R (typically feeding a hydraulic accumulator).

The compensator spool rest position has both ways $\left(\mathrm{A}_{R}\right.$ and $\left.\mathrm{A}_{T}\right)$ open. Along its stroke ( $\left.\mathrm{x}_{\text {COMP }}\right)$, it first closes the notch $A_{T}$ and then the notch $A_{R}$, so as to achieve a throttling function which preferably conveys the meter out flow towards the energy recovery line $\mathrm{R}$.

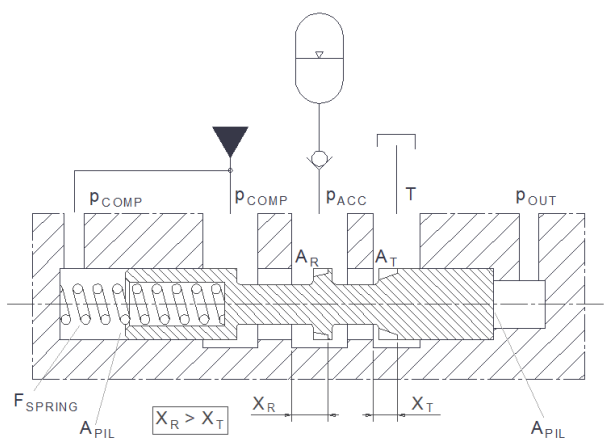

Figure 2: Downstream compensator concept

It is interesting to notice that the compensator does not need additional devices or pressure signals to provide for the correct regulation of the meter out flow: in case the $\mathrm{R}$ line cannot accept further flow due to the high accumulator pressure level ( $\left.\mathrm{p}_{\mathrm{ACC}}\right)$, the discharge flow will be redirected to the system tank, without compromising the actuator speed.

It is also worth to highlight that the whole system is achieving its functionality with a completely mechanical design, without the support of any electronic control. The valve section design is quite simple, consisting in a main spool and in a compensator spool as the most of typical Load Sensing valves. It follows that the additional costs of the system reside in the Re-Use System, which is not in the purpose of this paper, but is briefly discussed in paragraph 6.

\subsection{System tuning}

The system as described above is based on the serial connection of two flow control systems, working respectively on meter in $\mathrm{Q}_{\mathrm{IN}}$ and meter out Qout flows: the first characterized by the pump margin and the second characterized by the downstream compensator margin.

In some respect it can be assimilated to an Independent Metering system, where the delivered flow and the discharged flow have to be correctly managed and matched, in order to allow the correct behavior and avoid unexpected pressure increase [12].

In this case, a simple and cost-effective solution is given by providing a precise tuning of meter areas $A_{I N}$ and Aout and of pressure drops $\Delta \mathrm{p}_{\mathrm{IN}}$ and $\Delta$ pout.

Feeding, for instance, the bottom side of a cylinder actuator with $A / a$ areas ratio, the following equation must always be respected for any position XspooL of the main spool:

$$
A_{I N} \cdot \sqrt{\Delta p_{I N}} \cdot a / A \leq A_{\text {OUT }} \cdot \sqrt{\Delta p_{\text {OUT }}}
$$

Whenever a section is actuating a positive opposing load, the pump margin control (meter in) prevails.

Whenever a section is actuating a negative overrunning load, the downstream compensator margin control (meter out) prevails.

In case of simultaneous operations, the compensator of the lower pressure section will throttle the meter out line, in order to set the correct flow.

The described system tuning inevitably involves a slight difference in the regulated flow, according to different working conditions. However, simulations and experimental tests have shown that this difference can be contained in values that are more than acceptable for the normal needs of operating machines.

The three ways compensator design allows to recover energy from both overrunning loads control and compensation of simultaneous operations at different working pressures.

Looking at typical $\mathrm{p}-\mathrm{Q}$ hydraulic power diagrams for a load lifting/lowering operation 
and for a two actuators simultaneous operation, it is possible to identify the potential recovery.

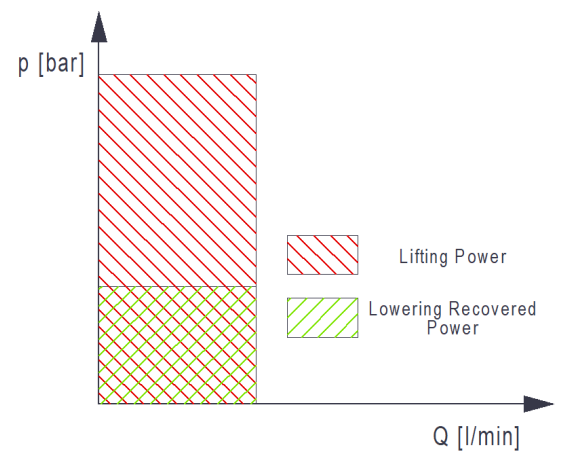

Figure 3: Recovery from overrunning loads

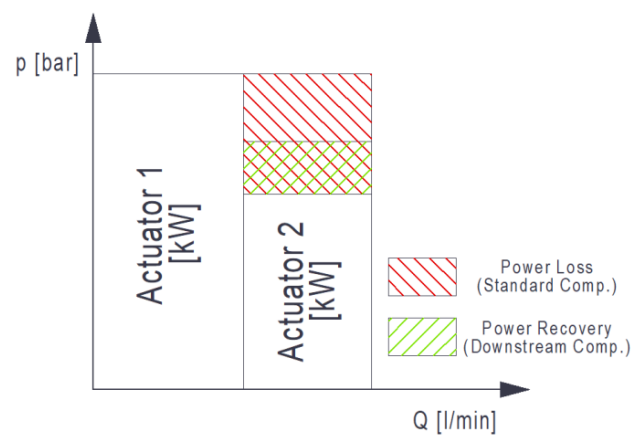

Figure 4: Recovery from simultaneous operations

Recovery from negative loads and from simultaneous operations have been studied separately through simulation and laboratory tests to evaluate the respective contribution to energy saving.

\section{ENERGY RECOVERY FROM NEGATIVE LOADS (OVERRUNNING)}

\subsection{Simulation Model}

A simple circuit has been simulated by a lumped parameter model to study the downstream compensator behavior and its capability to recover energy from overrunning loads.

The effect of the external overrunning load is simulated through a pump, feeding the directional control valve and through a main relief valve to set the load pressure on meter out line.

The simulation consists in displacing the main spool, opening the Aout notches to a fixed value and verifying the accumulator filling effect (the filling is typically fast enough to be considered adiabatic) and the speed control consistency when the accumulator has reached its maximum capacity and the out flow is diverted to tank.

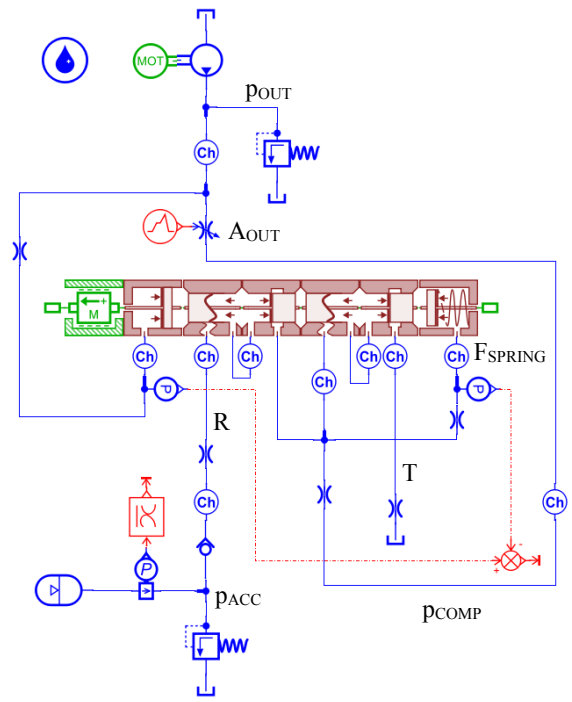

Figure 5: Simulation model overrunning loads

\subsection{Experimental tests}

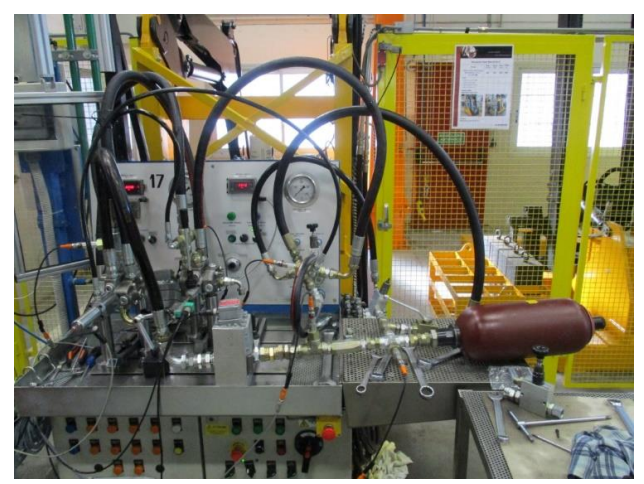

Figure 6: Experimental test setup for overrunning loads

The simulated system has been recreated in laboratory through the use of existing components and through the manufacturing of a dedicated manifold for the compensator subsystem.

A $6 \mathrm{~L}$ accumulator with 35 bar precharge has been used during the test.

The test demonstrates the system capability to recover energy, without any effect on actuator speed. 
The following diagrams show the result of experimental activity (continuous line) compared with simulation outputs (dotted line).

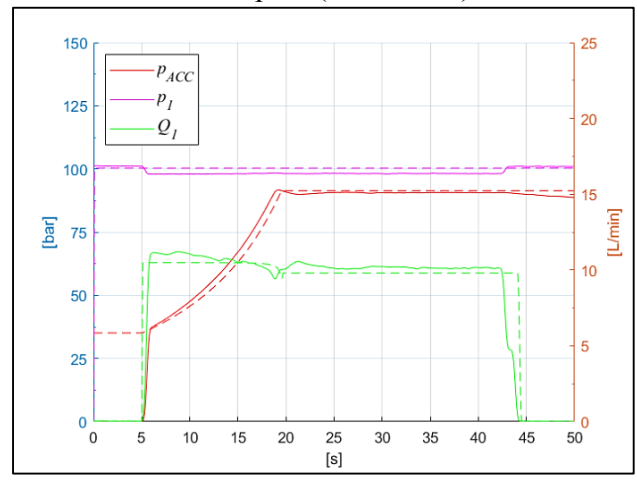

Figure 7: Controlled flow, load pressure and accumulator pressure

Figure 7 shows the pump pressure set at the constant value of $100 \mathrm{bar}$, the $10 \mathrm{~L} / \mathrm{min}$ controlled flow and the increasing pressure of the accumulator. The transition from the recovery position to the tank position is smooth and does not affect the speed control and the movement continuity.

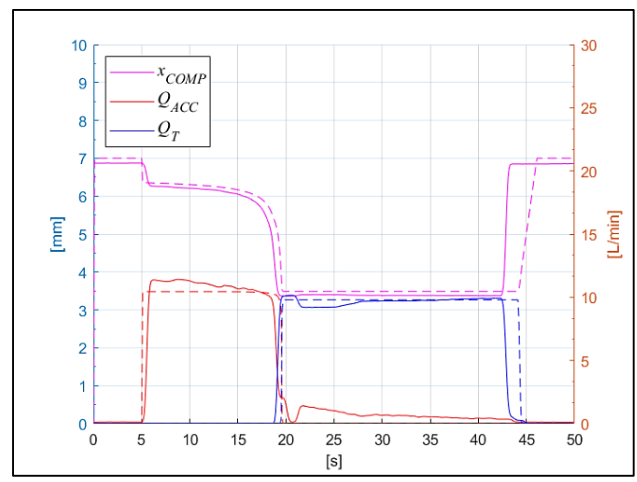

Figure 8: Compensator displacement, flow to $\mathrm{R}$ line, flow to $\mathrm{T}$ line

Figure 8 shows the compensator displacement and the consequent change of discharged flow from $\mathrm{R}$ line to $\mathrm{T}$ line. The test also confirms that the speed control depends on the main spool stroke and not on the load pressure level.

\section{ENERGY RECOVERY FROM SIMULTANEOUS (COMPENSATION)}

\subsection{Simulation Model}

The complete system, given by the combination of two sections driving two actuators, has been simulated by a lumped parameter model.

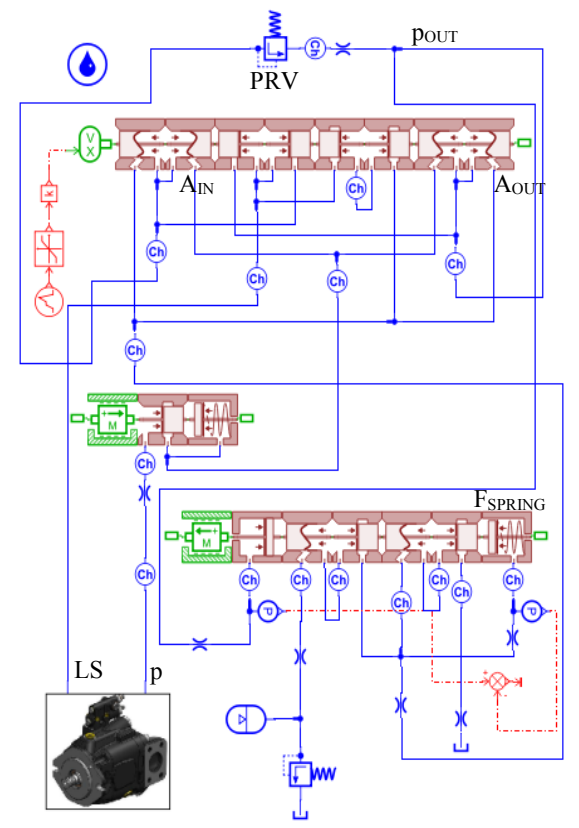

Figure 9: Single section model

The single section model shown in Figure 9 is composed by the main spool and its check valve model, the compensator model and the pump model, which has been kept quite simple for simulation time convenience.

The single section model has been then duplicated in a larger model for the simultaneous operations analysis.

The load is applied by means of a pressure relief valve (PRV) simulating a motor type actuator.

Basic analysis and attempts have been run on this model to prove the correct behavior of the system and to optimize some of the components dimensioning and design. 


\subsection{Experimental tests}

The two sections system has been eventually recreated on a test bench for experimental test. A preliminary testing work was necessary to match the real set up and the simulation model parameters and sizing.

After finding a complete correspondence of the basic functions, several concept-proving tests have been run.

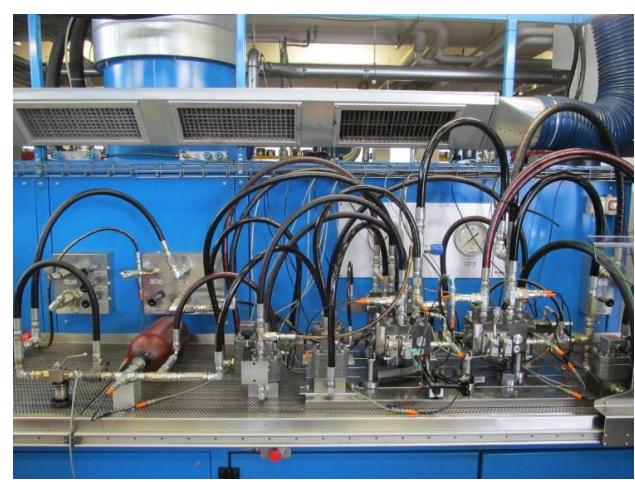

Figure 10: Experimental test setup for simultaneous operations

The system has been equipped with specific directional control valves and with a $6 \mathrm{~L}$ and 35 bar precharged accumulator to store the recovered flow. Moreover, different pressure and flow sensors have been inserted to thoroughly analyze the behavior of every single component. Unfortunately, the complexity of the piping has resulted in additional pressure drops that can be easily avoided in an optimized circuit. Furthermore, a structural limit of the components has limited the system maximum test pressure to 120 bar.

This paragraph explains one of the most interesting experimental tests: the cross compensation test.

Two sections are operated simultaneously. Section 1 is actuated to deliver a constant $40 \mathrm{~L} / \mathrm{min}$ flow $\left(\mathrm{Q}_{\mathrm{IN}-1}\right)$ at a constant 40 bar load $\left(\mathrm{p}_{1}\right)$; Section 2 is actuated to deliver a constant $40 \mathrm{~L} / \mathrm{min}$ flow $\left(\mathrm{Q}_{\mathrm{IN}-2}\right)$ at a load pressure $\left(\mathrm{p}_{2}\right)$ increasing from 15 bar to 110 bar.

After $27 \mathrm{~s}$ test time, the loads cross is happening: before this point Section 1 has the higher load and therefore its compensator is fully open; after this point Section 1 has the lower load and its compensator starts throttling. The opposite is happening for Section 2.

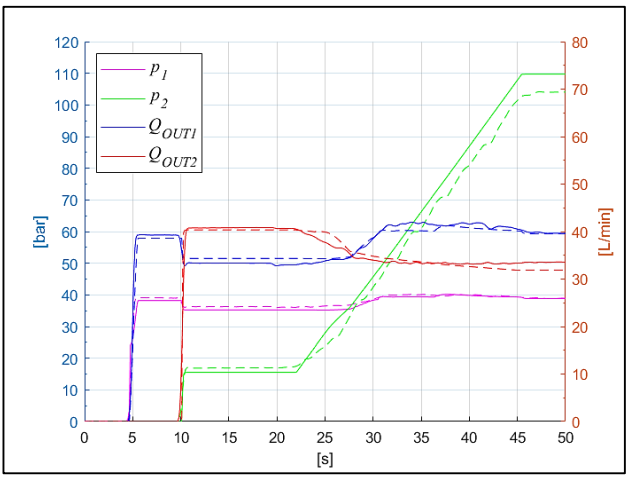

Figure 11: Delivered flows and load conditions

Figure 11 shows Section 1 and Section 2 delivered flows and loads condition. It also shows in dotted line the result from lumped parameter simulation and in continuous line the results of experimental testing.

The difference in the delivered flows during the compensating work depends partially on the system tuning explained in paragraph 2.2 and partially on high distributed pressure drops occurring in the non-optimized prototype layout. Figures 12 and 13 show other significant details during the same test.

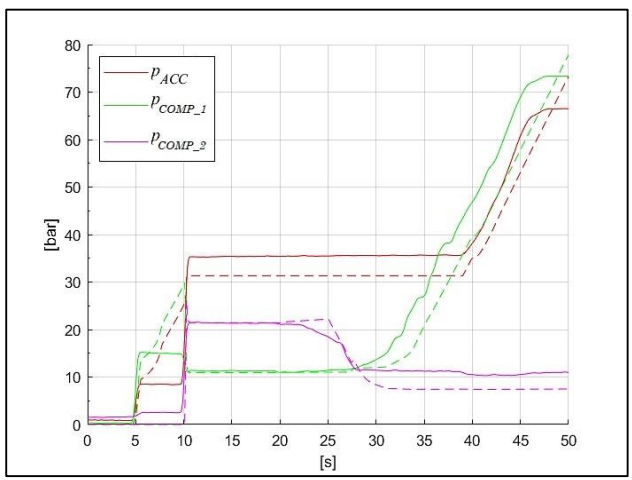

Figure 12: Compensators regulated pressure and accumulator pressure

Figure 12 shows the downstream compensators work: the p $_{\text {COMP-1 }}$ and p $_{\text {COMP-2 }}$ pressures indicate that the relative compensators are throttling to control the actuators speed. The diagram also shows the increasing pressure of the accumulator over the test time. 


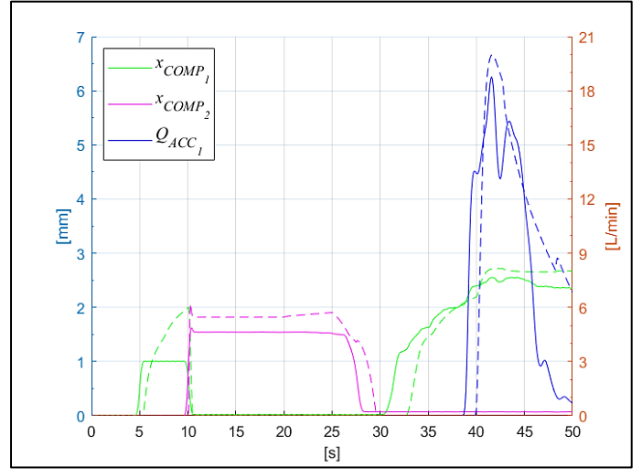

Figure 13: Compensators displacement and flow to accumulator

Figure 13 shows the compensators stroke $\mathrm{x}_{\mathrm{COMP}-1}$ and $\mathrm{x}_{\mathrm{COMP}-2}$ and the amount of recovered flow redirected by the compensators to the $\mathrm{R}$ line and to the accumulator.

\section{EFFICIENCY ANALYSIS}

The contribution to energy recovery for the two operating modes (overrunning load and simultaneous operations) can be studied separately.

\subsection{Efficiency with overrunning loads}

In case of overrunning loads, we will consider the efficiency with reference to the energy required to lift a given cylinder load during a time $\mathrm{T}$.

The lift energy is ideally considered identical to the potential energy stored in the lifted cylinder:

$$
\int_{0}^{T} p \cdot Q_{I N} d t
$$

The recovered energy can be calculated as:

$$
\int_{0}^{T} p_{A C C} \cdot Q_{A C C} d t
$$

The efficiency results as:

$$
\eta_{\text {low }}=\frac{\int_{0}^{T} p_{A C C} \cdot Q_{A C C} d t}{\int_{0}^{T} p \cdot Q_{I N} d t}
$$

The recovered energy can also be calculated as the difference between the potential available energy of the lifted cylinder minus the distributed system losses, the energy losses in the main spool tank notch (Aоut) and the energy losses in the compensator throttling restrictions $\left(\mathrm{A}_{\mathrm{R}}\right.$ and $\left.\mathrm{A}_{\mathrm{T}}\right)$ :

$$
\begin{aligned}
& \int_{0}^{T} p_{\text {ACC }} \cdot Q_{A C C} d t= \\
& =\int_{0}^{T} p \cdot Q_{I N} d t-E_{\text {System Losses }}+ \\
& -\int_{0}^{T}\left(p_{\text {OUT }}-p_{\text {COMP }}\right) \cdot Q_{\text {OUT }} d t+ \\
& -\int_{0}^{T}\left(p_{\text {COMP }}-p_{A C C}\right) \cdot Q_{R} d t+ \\
& -\int_{0}^{T} p_{\text {COMP }} \cdot Q_{T} d t
\end{aligned}
$$

For some specific configurations, in which the accumulator is properly sized accordingly to the specific cylinder and load condition, a recovery efficiency over $60 \%$ has been found.

In real working conditions the recovery efficiency is limited by the following aspects:

- The accumulator is not big enough to further receive discharged flow and it starts to divert the flow to tank

- The accumulator is too big and, due to the low pressure level reached, the recovered energy is less

- The accumulator precharge pressure is too high and does not allow to recover from low loads

- The accumulator precharge pressure is too low and the compensator generates high pressure drop to control the flow

The diagram in Figure 14 shows the simulations at different loads. It displays the contribution of Equation 8 losses, considering a system with a $12 \mathrm{~L}$ accumulator and with 35 bar precharge.

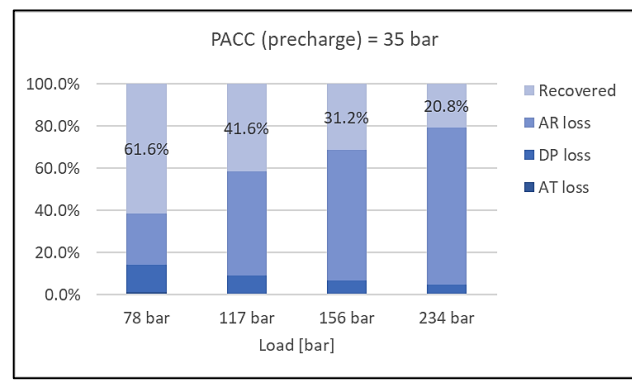

Figure 14: 35 bar precharge, various loads simulation

In this scenario the accumulator is big enough to receive the complete flow from the cylinder (almost no flow toward tank and no losses through the $\mathrm{A}_{\mathrm{T}}$ notch in the compensator are 
occurring); the distributed system losses are omitted; the pressure drop (DP loss) across the main spool Aout notch has a constant value (due to the same Qout flow at the same $\Delta$ pout), even though its per cent relevance is decreasing as the whole energy amount is increasing.

The recovered energy is decreasing as the load increases, due to the fact that the loss through the $A_{R}$ notch of the compensator is increasing.

Figure 15 shows the results in case the accumulator precharge is raised to 70 bar:

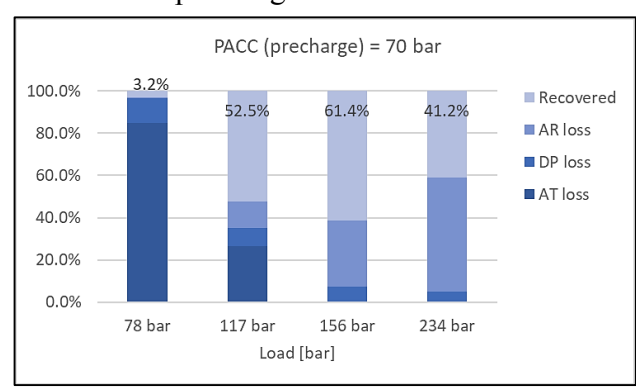

Figure 15: 70 bar precharge, various loads simulation

The high value of precharge does not allow the correct lowering speed with 78 bar and 117 bar loads, so that a considerable amount of energy is wasted through the $\mathrm{A}_{\mathrm{T}}$ compensator notch.

When the load is high enough to allow the correct speed with 70 bar precharge, the behavior resembles to the previous case: the system efficiency is having a maximum over $60 \%$ and then it decreases again as the load increases.

In real application on mobile machines, a compromise configuration that maximizes the recovery in the different and most usual working conditions has to be found.

It should also be noticed how the maximum efficiency about $60 \%$ is given by some fixed losses in the circuit: the piping distributed loss, the localized pressure drop through the main spool notch $A_{\text {OUT }}$ and the localized pressure drop through the compensator $A_{R}$ notch. A better layout, a different choice for the $\Delta \mathrm{P}_{\text {OUT }}$ pressure drop and especially an improved dimensioning $\left(A_{R}\right.$ and $\left.A_{T}\right)$ and phasing $\left(x_{R}\right.$ and $\left.x_{T}\right)$ of the compensator notches can sensibly increase this maximum efficiency value.

\subsection{Efficiency with simultaneous operations}

When considering simultaneous actuations, the best is to evaluate the recovery potential with regards to the energy loss that a traditional Load Sensing compensated system is generating to keep the speed control of the less charged actuator.

Considering a Section 1, delivering a flow $\mathrm{QIN}_{\text {- }}$ 1 with a high load $p_{1}$ and a Section 2, delivering a flow $Q_{\text {IN-2 }}$ with a lower load $p_{2}$, the energy loss in traditional LS systems can be calculated as follow:

$$
\int_{0}^{T}\left(p_{1}-p_{2}\right) \cdot Q_{I N-2} d t
$$

While recovered energy is still represented by the equation:

$$
\int_{0}^{T} p_{A C C} \cdot Q_{A C C} d t
$$

The efficiency results as:

$$
\eta_{\text {comp }}=\frac{\int_{0}^{T} p_{A C C} \cdot Q_{A C C} d t}{\int_{0}^{T}\left(p_{1}-p_{2}\right) \cdot Q_{I N-2} d t}
$$

In this case as well, the amount of recovered energy can be sensibly different depending on the parameters: approximately the same sizing problems described in the case of overrunning loads are the reasons for a reduction in efficiency. The recovery efficiency is strongly reduced by the throttling of compensator when the loads $p_{1}$ and $\mathrm{p}_{2}$ are sensibly different.

The recovery efficiency is further reduced when the accumulator improper sizing forces the compensator to divert the flow toward tank.

\subsection{Efficiency of tested layouts}

Considering the two systems tested in experimental activity described in paragraphs 3.2 and 4.2 , it must be clarified that main focus was to verify the functionality and practical feasibility of the innovative system.

The system efficiency optimization, as a secondary target, was limited by non-optimized components, complex piping and instrumentation. Nevertheless, interesting results have confirmed the expectations of simulation activity:

- Overrunning load test described in paragraph 3.2 showed a recovery of $60 \%$ of the equivalent lifting energy. The simulations allow to identify the optimal dimensioning of the accumulator volume (indicatively two times the cylinder volume to be discharged) and its precharge 
pressure (indicatively 2.5/3 times lower than the applied load).

- Simultaneous movements test described in paragraph 4.2 showed a recovery of $16 \%$ of the energy normally wasted in analogous compensation work in traditional LS system. Additional simulations have shown that the correct accumulator precharge level and volume can increase the recovery up to $65 \%$.

\section{STORAGE SYSTEM}

An accumulator is provided to store the recovered energy; check valves on $\mathrm{R}$ lines prevent the possibility of flow back.

The methods to re-use the hydraulic energy stored in the accumulator are not covered in this paper. However, some solutions have been evaluated, envisaging the use of a hydraulic motor connected to the ICE shaft in order to sustain the torque required by the system [2]. A second solution involves a hydraulic motor connected to an electric generator aimed to the battery recharge in a hybrid or totally electrified machine [13][14].

To a first approximation, the hydraulic accumulator could be omitted, although the simulations have shown that the presence of a hydraulic buffer allows to manage in a more efficient way the high and discontinuous power typically recovered from machine operations. It further allows to reduce the size of the components dedicated to re-use.

It should obviously be pointed out that the energy Re-Use system itself could reduce the whole system efficiency.

\section{CONCLUSION}

The paper presents an innovative directional valve layout for the control of the flow to the actuators of a mobile machine, in which a "downstream compensation" system allows to intercept hydraulic energy flows from inertial movements and from the simultaneous activation of loads at different values of pressure.

A first benefit is the possibility to control overrunning loads speed as a function of main spool displacement.

The experimental tests have proved the controllability of the system and the correct and smooth behavior of the downstream compensator.

Furthermore, the system allows for a substantial energy recovery, which has been experienced on test bench.

The amount of recovered energy is strongly dependent on the complete hydraulic circuit parameters and on the machine use mode: several analyses have brought to find the rules for optimal sizing, which can be consequently applied to different types of machine.

\section{OUTLOOK}

The next activities will concern the analysis of the energy benefits of the system applied on specific types of machines and in realistic work cycles.

Especially the method to provide the correct and best compromise sizing of the system will be approached.

At the same time, an industrialized and commercially viable form of the concept will be developed. Furthermore, particular attention will be paid to the methods to re-use the stored energy: different concepts are going to be proved and evaluated in terms of whole system efficiency.

\section{FUNDING}

This research had developed as part of a $\mathrm{PhD}$ program supported by CNR (Consiglio Nazionale delle Ricerche) and Confindustria, operative convention May 2018.

\section{NOMENCLATURE}

$a / A \quad$ Cylinder areas ratio

$A_{I N} \quad$ Main spool metering in area

$A_{\text {OUT }} \quad$ Main spool metering out area

$A_{P I L} \quad$ Compensator piloting area

$A_{R} \quad$ Compensator way to recovery line

$A_{T} \quad$ Compensator way to tank line

$\Delta p_{I N} \quad$ Pressure drop through metering in area

$\Delta p_{\text {OUT }}$ Pressure drop through metering out area

$F_{\text {SPRING }}$ Compensator spring force

$L S \quad$ Highest Load Sensing pressure

$p \quad$ Pump pressure

$p_{A C C} \quad$ Accumulator pressure

$p_{\text {COMP }}$ Pressure between main spool and compensator

$p_{\text {OUT }}$ Pressure on actuator meter out line

$p_{P R E} \quad$ Accumulator precharge pressure

$Q_{A C C} \quad$ Flow direct to the accumulator

$Q_{I N} \quad$ Flow to the user (meter in flow)

$Q_{\text {OUT }}$ Flow from the user (meter out flow)

$Q_{R} \quad$ Flow on the recovery line 
$Q_{T} \quad$ Flow on the tank line

$x_{\text {COMP }}$ Compensator stroke

$x_{S P O O L}$ Main spool stroke

$x_{R} \quad$ Underlap way to recovery line

$x_{T} \quad$ Underlap way to tank line

$\eta_{\text {low }} \quad$ Efficiency in lowering test

$\eta_{\text {comp }}$ Efficiency in simultaneous operations test

\section{REFERENCES}

[1] Lodewyks J, Zurbrügg P (2016) Decentralized energy-saving hydraulic concepts for mobile working machines, 10th International Fluid Power Conference, Dresden, Germany

[2] Casoli P, Riccò L, Campanini F, Dolcin C, Lettini A (2016) Hydraulic Hybrid Excavator: Layout Definition, Experimental Activity, Mathematical Model Validation and Fuel Consumption Evaluation, 10th International Fluid Power Conference, Dresden, Germany

[3] Vukovic M, Leifeld R, Murrenhoff H (2016) STEAM - Hydraulic hybrid architecture for excavators, 10th International Fluid Power Conference, Dresden, Germany

[4] Schneider M, Koch O, Weber J, Bach M, Jacobs G (2014) Green Wheel Loader - Development of an energy efficient drive and control system, 9th International Fluid Power Conference, Aachen, Germany

[5] Inderelst M, Weidner F, Dongdong N, Stammen C (2018) Quantification of Energy Saving Influencers in a 21t Excavator Hydraulic System - A Holistic Investigation, 11th International Fluid Power Conference, Aachen, Germany

[6] Salomaa V, Mattila J, Minav T, Pietola M (2018) Efficiency Study of an Electro-Hydraulic Excavator, 11th International Fluid Power Conference, Aachen, Germany
[7] Busquets E, Ivantysynova M (2016) Toward Supervisory-Level Control for the Energy Consumption and Performance Optimization of Displacement-Controlled Hydraulic Hybrid Machines, 10th International Fluid Power Conference, Dresden, Germany

[8] Bonavolontà A, Dolcin C, Marani P, Frosina E, Senatore A (2019) Comparison of Energy Saving and Recovery Systems for Hydraulic Mobile Machines, $74^{\text {rd }}$ Conference of the Italian Thermal Machines Engineering Association, ATI 2019, Modena, Italy

[9] Siebert J, Geimer M (2016) Reduction of System Inherent Pressure Losses at Pressure Compensators of Hydraulic Load Sensing Systems, 10th International Fluid Power Conference, Dresden, Germany

[10] Marani P, Ansaloni G, Paoluzzi R (2008) Load Sensing with Active Regeneration System, Proc.s Of The 7th Japan International Fluid Power Symposium, Toyama, Japan

[11] Marani P, Milani M, Mesturini D, Busani U. (2018) Experimental Evaluation of the New Meter Out Sensing Architecture, 11th International Fluid Power Conference, Aachen, Germany

[12] Sitte A, Weber J (2013) Structural design of independent metering control systems, The 13th Scandinavian International Conference on Fluid Power, Linköping, Sweden

[13] Tianliang Lin, Qingfeng Wang, Baozan $\mathrm{Hu}$, Wen Gong (2010) Development of hybrid powered hydraulic construction machinery, Automation in Construction 19 (2010)

[14] Lei Ge, Long Quan, Xiaogang Zhang, Jaihai Huang, Bin Zhao (2018) High Energy Efficiency Driving of the Hydraulic Excavator Boom with an Asymmetric Pump, 11th International Fluid Power Conference, Aachen, Germany 